IP Periodica Polytechnica

Transportation Engineering

43(1), pp. 48-54, 2015

DOI: 10.3311/PPtr.7739

Creative Commons Attribution (i)

RESEARCH ARTICLE

\section{Mapping the Opportunities of Rail Transport; a Data-Driven Methodology for Capturing Rail Competitiveness at European Level}

\author{
Georgia AIFANDOPOULOU ${ }^{1 *}$, Iraklis STAMOS ${ }^{1}$ \\ Glykeria MYROVALI ${ }^{1}$, Maria MORFOULAKI ${ }^{1}$
}

Received 01 October 2014; Accepted 09 October 2014

\begin{abstract}
The current paper focuses its study on the Southeast Europe (SEE) and tries to identify real passenger needs (demand) which can reveal rail dynamic and competitiveness in specific connections. Based on a dedicated examination of 11 SEE city hubs (Bologna, Venice, Trieste, Ljubljana, Vienna, Bratislava, Budapest, Thessaloniki, Sofia, Zagreb and Bucharest) examined within "Rail4SEE - Rail Hub Cities for South East Europe" project, the paper aims to conclude in a quantitative analysis of demand data at regional and transnational level and on a comparative analysis based both on demand and supply data that will open the ground for the development of an accurate SEE modal split model.
\end{abstract}

\section{Keywords}

Rail hubs, South East Europe, Passengers, Demand, Data, Rail Competitiveness

\footnotetext{
${ }^{1}$ CERTH - HIT, Principal Research Scientist I, Head of Sector B: "Surface Transport and Networks", 6th km Charilaou - Thermi Road - P.O. Box 60361 - 57001 Thermi, Thessaloniki, Greece

*Corresponding author, email: gea@certh.gr
}

\section{Introduction}

Through its guidelines and directions, the EU opens the crevice for strengthening public transport (PuT) sector and ensuring its competitiveness for achieving its wider target, this of future sustainability (Commissie, 2011). The reinforcement of rail sector falls within this general objective given the fact that is a PuT subsector that can contribute to the fulfillment of the vision for a "Resource Efficiency Europe" since can contribute the most in reducing oil dependency in comparison with the other transport subsectors (The Council, 2013; Eisenkopf et al., 2006). This scope, however, can only be met if rail sector achieve to provide modern, safe, efficient and integrated services able to respond to real passengers' needs. (EC Directorate General for Energy and Transport, 2008; Török, 2014)

The rail transport reality in Europe is unfavorable however; railways started fighting for keeping a decent modal share from the early '60s; rail's strong competitor, private car, due to its inherent advantage of door-to-door transportation, started following a continuous upward trend in short and medium distance trips. Low cost airlines from the other side started becoming a good alternative for longer distances. Rail decline in recent decades becomes obvious; from $10 \%$ in 1970 (EU-15) fell down $6.9 \%$ in 2006 in the EU-27 (World Bank, 2011). Since 2006 , rail holds a percentage of $6 \%$ more or less. Even a drop of $20 \%$ in some cases (Sweden) was also observed in domestic rail trips from 2005 to 2010 (Eisenkopf et al., 2006). Excluding sustainability issues (rail is not inefficient for shorter distance urban journeys and of course not able to transport as far as air transport can), operational and governance issues are to be blamed for rail decline; insufficient infrastructure, bad condition of rolling stock, interoperability obstacles, governance of railways, monopolies and absence of incentives for further rail investment and development. And as if that internal issues were not enough, simultaneously policies supporting rail competitors, road and air transportation, harmed even more rail.

As regards Southeast Europe, SEE, the reality seems to be the same more or less; progress has collapsed and rail transportation remain in a hard position; SEE railways experienced significant declines in traffic volumes after 2008 as a result of the 
Table 1 Rail share at European Countries, 1990-2011, Source: (World Bank, 2011)

\begin{tabular}{|c|c|c|c|c|c|c|c|c|c|c|c|c|c|c|c|c|}
\hline \multicolumn{17}{|c|}{ Railways } \\
\hline & & & & & & \multicolumn{11}{|c|}{$\begin{array}{l}\text { thousand mio } \\
\text { pkm }\end{array}$} \\
\hline & 1990 & 1995 & 2000 & 2001 & 2002 & 2003 & 2004 & 2005 & 2006 & 2007 & 2008 & 2009 & 2010 & 2011 & $\begin{array}{c}\text { change } \\
10 / 11 \\
\%\end{array}$ & \\
\hline EU27 & 400,7 & 350,5 & 370,7 & 372,7 & 365,6 & 361,9 & 367,8 & 377,1 & 390,6 & 395,9 & 411,1 & 402,5 & 404,2 & 407,1 & 0,7 & EU27 \\
\hline EU15 & 268,9 & 276,1 & 309,4 & 314,1 & 311,7 & 310,0 & 316,9 & 327,6 & 340,2 & 345,9 & 361,7 & 356,6 & 360,0 & 362,7 & 0,8 & EU15 \\
\hline EU12 & 131,8 & 74,4 & 61,4 & 58,7 & 63,8 & 51,9 & 60,9 & 49,6 & 50,3 & 50,1 & 49,3 & 46,0 & 44,2 & 44,4 & 0,4 & EU12 \\
\hline $\mathbf{B E}$ & 6,5 & 6,8 & 7,7 & 8,0 & 8,3 & 8,3 & 8,7 & 9,2 & 9,6 & 9,9 & 10,4 & 10,4 & 10,4 & 10,4 & 0,1 & $\mathbf{B E}$ \\
\hline BG & 7,8 & 4,7 & 3,5 & 3,0 & 2,6 & 2,5 & 2,4 & 2,4 & 2,4 & 2,4 & 2,3 & 2,1 & 2,1 & 2,1 & $-1,5$ & BG \\
\hline $\mathbf{C Z}$ & 13,3 & 8,0 & 7,3 & 7,3 & 6,6 & 6,5 & 6,6 & 6,7 & 6,9 & 6,9 & 6,8 & 6,5 & 6,6 & 6,7 & 1,9 & $\mathbf{C Z}$ \\
\hline DK & 5,1 & 4,9 & 5,5 & 5,7 & 5,7 & 5,8 & 5,9 & 6,0 & 6,1 & 6,2 & 6,3 & 6,2 & 6,3 & 6,6 & 4,1 & DK \\
\hline DE & 61,0 & 71,0 & 75,4 & 75,8 & 70,8 & 71,3 & 72,6 & 74,9 & 78,8 & 79,1 & 82,4 & 81,2 & 83,0 & 85,0 & 2,3 & DE \\
\hline $\mathbf{E E}$ & 1,5 & 0,4 & 0,3 & 0,2 & 0,2 & 0,2 & 0,2 & 0,2 & 0,3 & 0,3 & 0,3 & 0,2 & 0,2 & 0,2 & $-1,8$ & $\mathbf{E E}$ \\
\hline IE & 1,2 & 1,3 & 1,4 & 1,5 & 1,6 & 1,6 & 1,6 & 1,8 & 1,9 & 2,0 & 2,0 & 1,7 & 1,7 & 1,6 & $-2,4$ & IE \\
\hline EL & 2,0 & 1,6 & 1,9 & 1,7 & 1,8 & 1,6 & 1,7 & 1,9 & 1,8 & 1,9 & 1,7 & 1,4 & 1,3 & 1,0 & $-28,3$ & EL \\
\hline ES & 15,5 & 16,6 & 20,1 & 20,8 & 21,2 & 21,1 & 20,4 & 21,6 & 22,1 & 21,9 & 24,0 & 23,1 & 22,4 & 22,8 & 1,8 & ES \\
\hline FR & 63,7 & 55,6 & 69,9 & 71,5 & 73,5 & 71,1 & 74,3 & 76,2 & 79,5 & 81,6 & 86,6 & 85,9 & 85,9 & 89,0 & 3,6 & FR \\
\hline IT & 44,7 & 46,7 & 49,6 & 50,1 & 49,3 & 48,7 & 49,3 & 50,5 & 50,9 & 49,7 & 49,5 & 48,1 & 47,3 & 43,3 & $-8,3$ & IT \\
\hline CY & - & - & - & - & - & - & - & - & - & - & - & - & - & - & - & CY \\
\hline $\mathbf{L V}$ & 5,4 & 1,4 & 0,7 & 0,7 & 0,7 & 0,8 & 0,8 & 0,9 & 1,0 & 1,0 & 1,0 & 0,8 & 0,7 & 0,7 & $-1,1$ & $\mathbf{L V}$ \\
\hline LT & 3,6 & 1,1 & 0,6 & 0,5 & 0,5 & 0,4 & 0,4 & 0,4 & 0,4 & 0,4 & 0,4 & 0,4 & 0,4 & 0,4 & 4,3 & LT \\
\hline $\mathbf{L U}$ & 0,2 & 0,3 & 0,3 & 0,3 & 0,3 & 0,3 & 0,3 & 0,3 & 0,3 & 0,3 & 0,3 & 0,3 & 0,3 & 0,3 & 0,6 & $\mathbf{L U}$ \\
\hline HU & 11,4 & 8,4 & 9,7 & 10,0 & 10,5 & 10,3 & 10,2 & 9,9 & 9,7 & 8,8 & 8,3 & 8,1 & 7,7 & 7,8 & 1,5 & $\mathbf{H U}$ \\
\hline MT & - & - & - & - & - & - & - & - & - & - & - & - & - & - & - & MT \\
\hline NL & 11,1 & 16,4 & 14,7 & 14,4 & 14,3 & 13,8 & 14,5 & 15,2 & 15,9 & 15,5 & 15,3 & 15,4 & 15,4 & 15,7 & 2,3 & NL \\
\hline AT & 8,9 & 10,1 & 8,7 & 8,8 & 8,8 & 8,7 & 8,7 & 9,5 & 9,3 & 9,6 & 10,8 & 10,7 & 10,7 & 10,9 & 1,3 & $\mathbf{A T}$ \\
\hline PL & 50,4 & 26,6 & 24,1 & 22,5 & 20,7 & 19,6 & 18,7 & 18,2 & 18,6 & 19,9 & 20,2 & 18,6 & 17,9 & 18,2 & 1,4 & PL \\
\hline PT & 5,7 & 4,8 & 4,0 & 4,0 & 3,9 & 3,8 & 3,7 & 3,8 & 3,9 & 4,0 & 4,2 & 4,2 & 4,1 & 4,1 & 0,8 & PT \\
\hline RO & 30,6 & 18,9 & 11,6 & 11,0 & 8,5 & 8,5 & 8,6 & 8,0 & 8,1 & 7,5 & 7,0 & 6,1 & 5,4 & 5,1 & $-6,7$ & RO \\
\hline SI & 1,4 & 0,6 & 0,7 & 0,7 & 0,7 & 0,8 & 0,8 & 0,8 & 0,8 & 0,8 & 0,8 & 0,8 & 0,8 & 0,8 & $-4,9$ & SI \\
\hline SK & 6,4 & 4,2 & 2,9 & 2,8 & 2,7 & 2,3 & 2,2 & 2,2 & 2,2 & 2,2 & 2,3 & 2,3 & 2,3 & 2,4 & 5,3 & SK \\
\hline FI & 3,3 & 3,2 & 3,4 & 3,3 & 3,3 & 3,3 & 3,4 & 3,5 & 3,5 & 3,8 & 4,1 & 3,9 & 4,0 & 3,9 & $-1,9$ & FI \\
\hline $\mathbf{S E}$ & 6,6 & 6,8 & 8,2 & 8,7 & 8,9 & 8,8 & 8,7 & 8,9 & 9,6 & 10,3 & 11,1 & 11,3 & 11,2 & 11,4 & 1,4 & SE \\
\hline UK & 33,4 & 30,3 & 38,4 & 39,4 & 39,9 & 41,2 & 43,3 & 44,4 & 47,0 & 50,2 & 53,0 & 52,8 & 55,8 & 56,6 & 1,4 & UK \\
\hline HR & 3,4 & 1,1 & 1,3 & 1,2 & 1,2 & 1,2 & 1,2 & 1,3 & 1,4 & 1,6 & 1,8 & 1,8 & 1,7 & 1,5 & $-14,7$ & HR \\
\hline MK & & 0,1 & 0,1 & 0,1 & 0,1 & 0,1 & 0,1 & 0,1 & 0,1 & 0,1 & 0,1 & 0,2 & 0,2 & 0,1 & $-6,5$ & MK \\
\hline TR & 6,4 & 5,8 & 5,8 & 5,6 & 5,2 & 5,9 & 5,2 & 5,0 & 5,3 & 5,6 & 5,1 & 5,4 & 5,5 & 5,9 & 7,1 & TR \\
\hline IS & - & - & - & - & - & - & - & - & - & - & - & - & - & - & - & IS \\
\hline NO & 2,1 & 2,4 & 2,6 & 2,7 & 2,5 & 2,4 & 2,6 & 2,7 & 2,8 & 3,0 & 3,1 & 3,0 & 3,1 & 3,0 & $-1,7$ & NO \\
\hline CH & 12,7 & 11,7 & 12,6 & 13,3 & 14,1 & 14,5 & 14,9 & 16,1 & 16,6 & 17,4 & 17,8 & 18,6 & 19,2 & 19,5 & 1,5 & CH \\
\hline
\end{tabular}


international financial crisis (EC Directorate General for Energy and Transport, and not only (regimes of railways strangled internal competition and gave further impetus to rail competitors).

Taking in mind rail importance in forming a livable future in transportation, as previously referred, EU has showed its will to reinforcing rail sector (4 railway packages in force and many other references to EU documents for this necessity). Governance of infrastructure, opening of the market, exploitation of alternative financial resources (combined services, PPPs etc), interoperability issues, ICT exploitation, innovative cooperation schemes with respect to real needs of passengers are currently at the crux of national policy makers agendas.

The exploitation of rail strengths can change the backdrop and open the path for sector's recovery; safe, environmentally friendlier and less polluting than other modes (especially in the context of climate change rail strengths lie chiefly in its energy efficiency and potential to be powered by a range of sustainable energy sources (Armstrong, Preston, 2010)), cheaper than road and air transport in cases as well as currently (high speed trains) often faster than flying even on long distance trips. The further utilization of rail potentials (opportunities) will without saying contribute to entering on a recovery path; land use constraints, i.e. for the construction of infrastructure that hampers other modes development, rail advantage to be in demand - from commuters for example, ICT exploitation, potential agreements for provision of combined services capable to compete doo-todoor transportation are a strong asset of railway industry.

A key to policy makers' hands for estimating future passenger flows in order to identify gaps and opportunities for intervention and for unlocking rail potentials are the accurate and reliable transport models. The success of modelling however is highly dependent on the accuracy of data collected. In any case, the importance of data for transport modelling, for interventions proposals and valuable decision-making procedures cannot be understated. Thus, accurate data result in efficient measures and policies proposals, identification of opportunities for substitutability of modes that derive from transport modelling approaches.

Having recognized the potential catalytic role of rail in future sustainability, this paper focuses on one part of Europe, the Southeast part (SEE) and tries to identify real passenger needs (demand) which can reveal rail dynamic and competitiveness in specific connections. Based on a dedicated examination of 11 city hubs in SEE (Bologna, Venice, Trieste, Ljubljana, Vienna, Bratislava, Budapest, Thessaloniki, Sofia, Zagreb and Bucharest) examined in the project "Rail4SEE - Rail Hub Cities for South East Europe" (South East Europe programme, Regional Policy's Territorial Cooperation, EU), the paper aims to start from an Observatory for transport demand in SEE that will act as a feeder to the Transnational Modal Split Model developed in the framework of RAIL4SEE project (Stamos et al., 2014) which in turn will conclude to the evaluation of proposed interventions for rail development (Aifandopoulou et al., 2014).

\section{Objectives, Methods and Materials}

With an ultimate scope to develop a clear quantitative and qualitative picture of passengers' flows in South East Europe, the paper focuses on the present SEE situation in terms of analysis of transport flows to fix a network of rail hubs. The main issues tackled concerns the collection of exiting data. Data collection was built on collecting and validating data from existing sources (literature review, other research projects, online and open databases, TRANSTOOLS, ETISplus, national sources Statistic Agencies, other research projects and previous efforts, e.g. SEETAC project). The paper adopts a multimodal perspective by investigating primarily rail and public transport flows (short and long distance) but also eventual integrations with sea and air transport. The territorial targets of the analyses are on the one hand the local and metropolitan level, by focusing on the feeding functions of rail hubs as well as on the organization of the metropolitan transport systems, and on the other hand at transnational level in order to understand transport flows among hubs. In particular, the paper aims to deliver the following (RAIL4SEE, 2012):

1. Data collection at regional and transnational level for all modes (demand)

2. Transnational supply data collection

3. Quantitative analysis of demand data at regional and transnational level

4. Comparative analysis based on demand and supply data

For the regional analysis the term of hub's catchment area was inserted defining as such, the geographical area from which a hub attracts trips. The exact definition of a catchment area is a customized procedure for every hub, since neighboring land uses and geographical extents to which a hub remains attractive (for its activities or connections) cannot be predefined for all cases. Thus, the catchment area's extent cannot be predetermined in a strict geographical context (i.e. a radius of $250 \mathrm{~km}$ around a city) as every hub represents a special case. The definition of the catchment area follows a NUTS 3 classification, due to previous models developed at European level used as reference models and the same applies also for the data collected. The following figure (Fig. 1) depicts the SEE area with the hubs considered in the Rail4SEE project in NUTS 3 classified regions.

\section{Results}

\subsection{Main Results of the Demand Data Analysis}

The first step of the demand and supply data analysis was the calculation of an accessibility indicator that was made by using economic potential measures (Bruinsma, Rietveld, 1993; Spence, Linneker, 1994). According to this measure, the accessibility of a node in a network is proportional to the spatial interaction between the node and all other nodes. The interaction between a node $i, i$ and a destination node $j, j$ is proportional to 


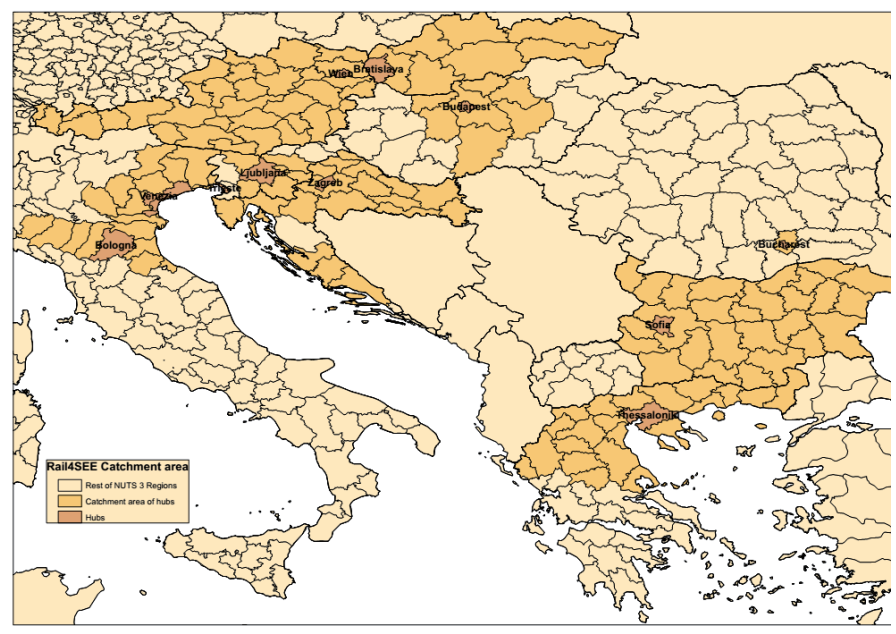

Fig. 1 The hubs of SEE considered in the Rail4SEE project in NUTS3

the size of that destination and inversely proportional to some power of the impedance to that destination (be it distance, travel time, etc. (Ficzere et al., 2014)) The mathematical formulation is given as follows:

$$
A_{i}=\sum_{j=1}^{n} \frac{M_{j}}{D_{i j}^{a}}
$$

where

$$
\begin{aligned}
& A_{i}=\text { the potential accessibility } \\
& M_{j}=\text { the size (attraction) of node } j \\
& D_{i j}=\text { the impedance between nodes } i \text { and } j
\end{aligned}
$$

For the needs of the specific study, a generalized impedance function based on travel time and cost is employed. The Value of Time indicator is used for a common unitary expression of the impedance.

The rail, road and air accessibility indicators are presented in the following maps and are given a first view for the role of every hub in the SEE region.

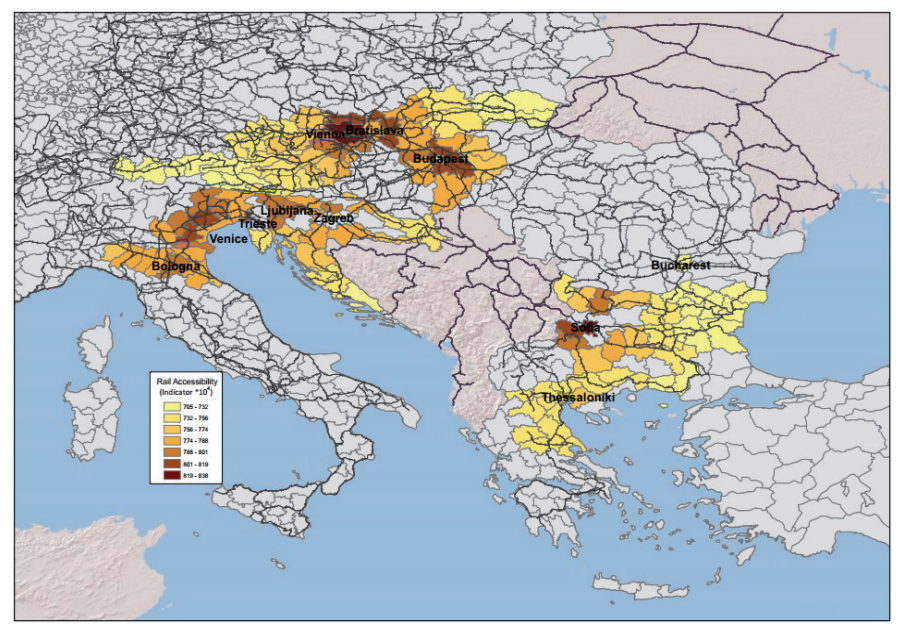

Fig. 2 Rail accessibility indicators for the SEE area

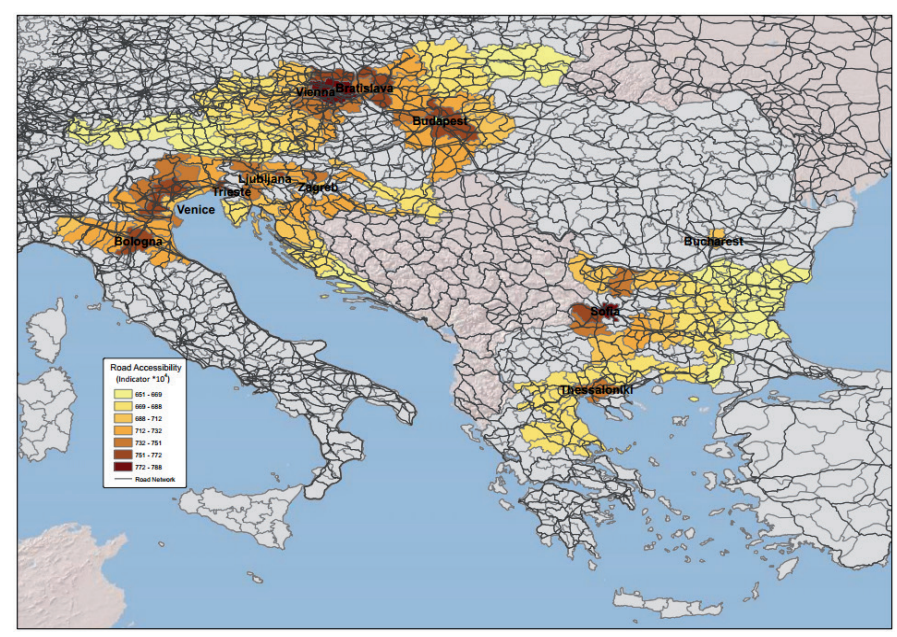

Fig. 3 Road accessibility indicators for the SEE area

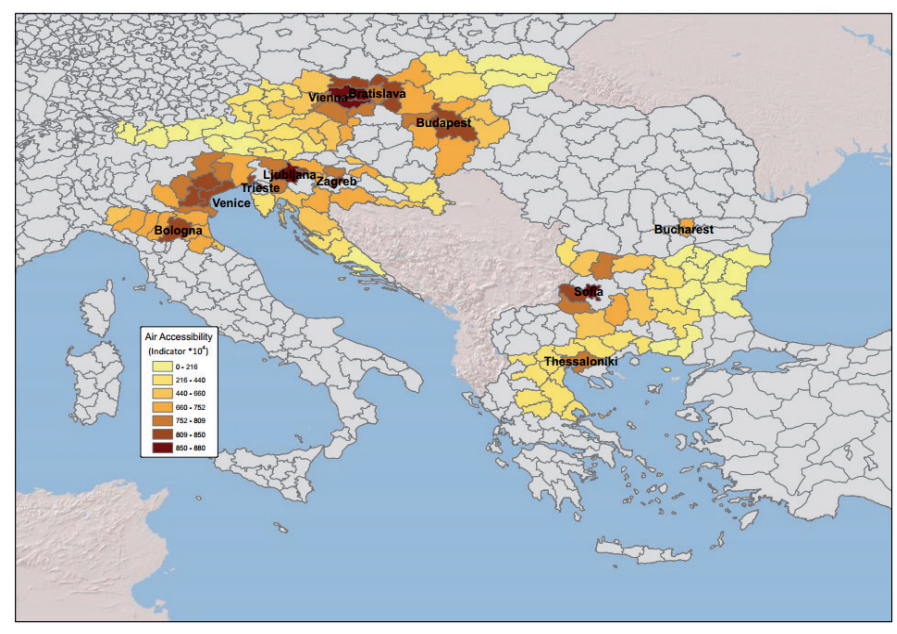

Fig. 4 Air accessibility indicators for the SEE area

The analysis of the regional demand was the second step of the presented procedure. From the current analysis, the most important regional rail connections for the 11 analyzed hubs that could eventually feed the transnational rail network are depicted in the following figure (Fig. 5):

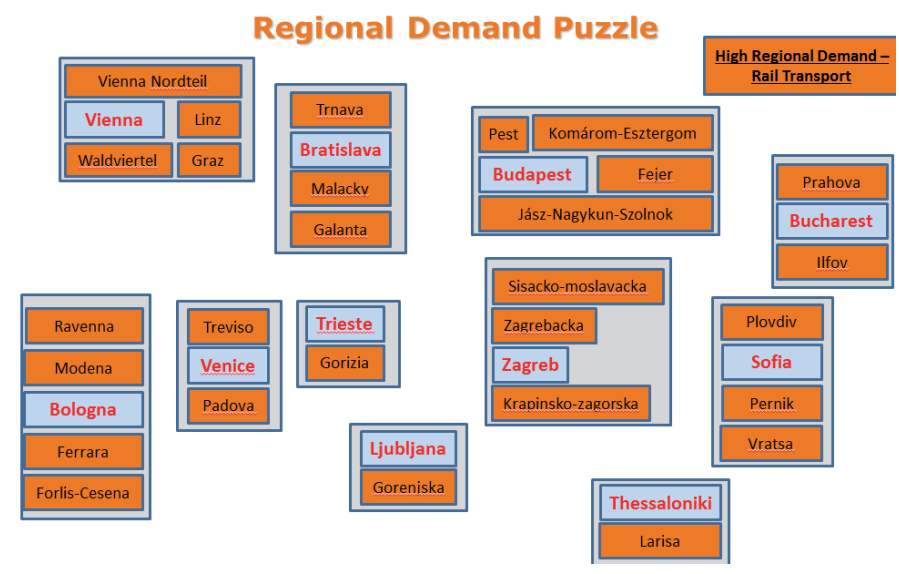

Fig. 5 Regional Demand - "Strong" Connections 
The analysis of the numeric Origin - Destination matrix between the 11 hubs of Rail4See project, representing annual passenger trips with each examined mode (rail, air, road) was the third step which concluding to the hubs with the higher number of international trips as well as to them with the higher use of rail mode for the execution of these trips (Fig. 6, Fig. 7).

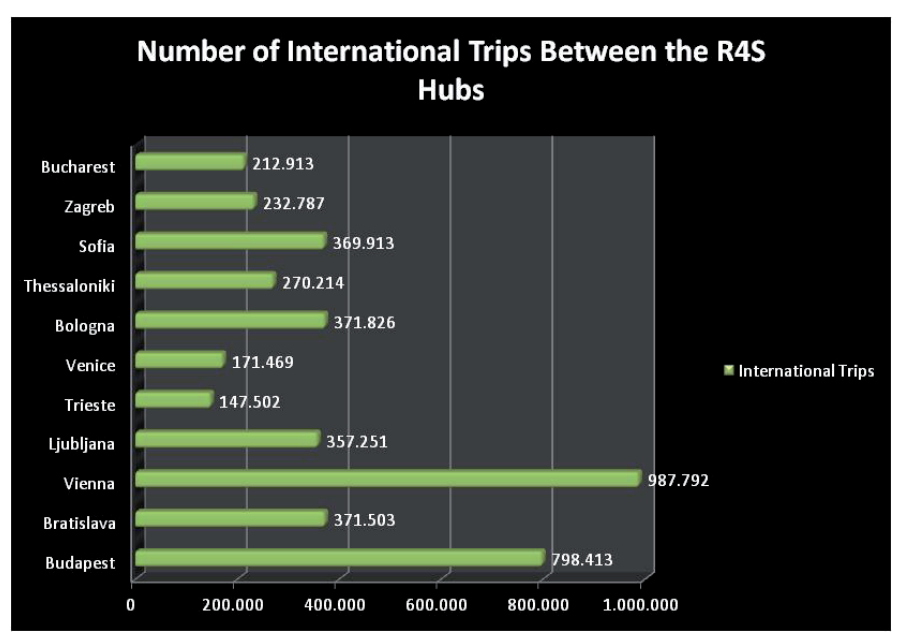

Fig. 6 Number of International Trips among R4S hubs

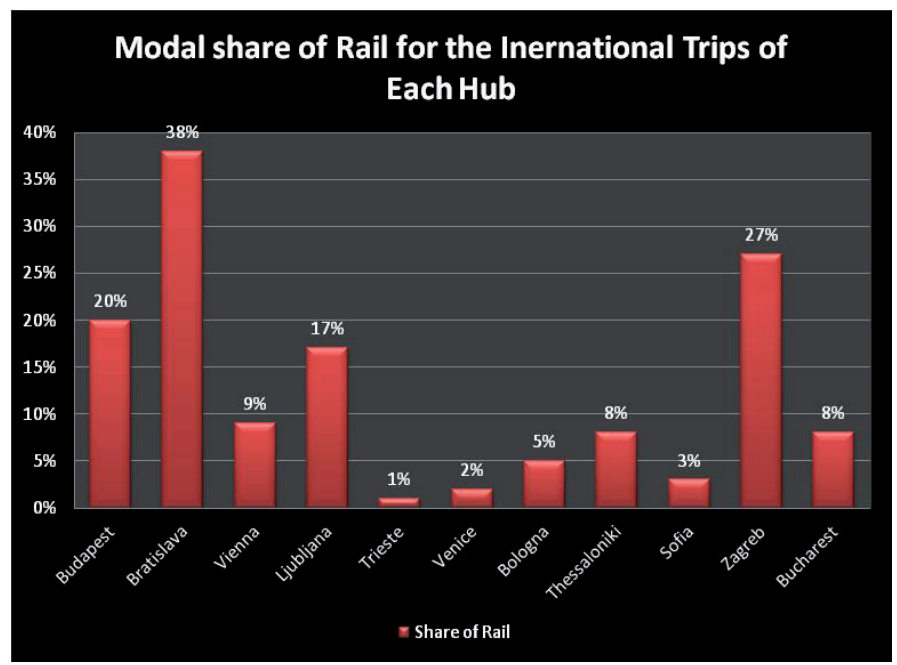

Fig. 7 Rail modal share at R4S hubs

According to the above results, the hub of Vienna and Budapest seems to be the two hubs which generate a lot of international trips. Nevertheless the use of rail is not so popular to Vienna - only $9 \%$ of the travelers use train for their international trips- while in Budapest the percentage is higher, reaching the $20 \%$. Regarding the connections with the major demand the following figure (Fig. 8) gives a clear view for the O-D pairs between the hubs which present high and medium number of travelers.

There are a lot of high demanding connections between the 11 hubs with annual trips that reach annual the number of 400 000. Budapest-Vienna, Bratislava-Budapest and
Thessaloniki-Sofia are presenting strong exchange of trips. In order to find out if the above mentioned needs can be covered, the fourth step of the analysis took place highlighting the competitive supply railway network.

\section{International Demand Puzzle}

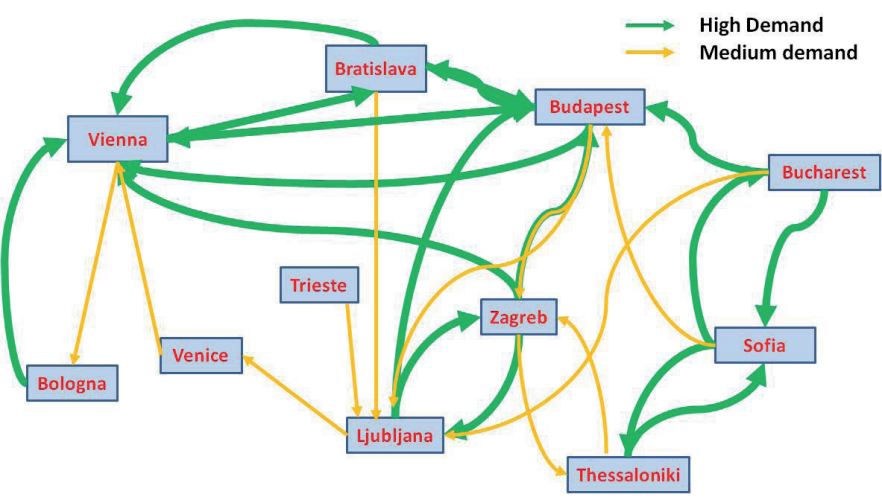

Fig. 8 International Demand - "Strong" Connections

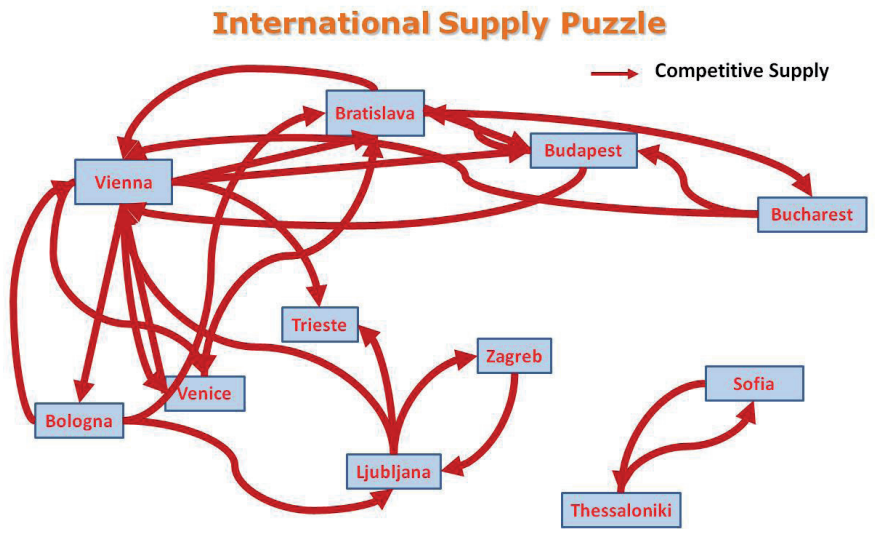

Fig. 9 International Supply - Competitive Supply

The next step of the analysis was the identification of improvement opportunities, combining demand and supply data between the 11 hubs. In the two figures that follow (Fig. 10, Fig. 11) the commonalities and the differentiations between demand and supply are presented.

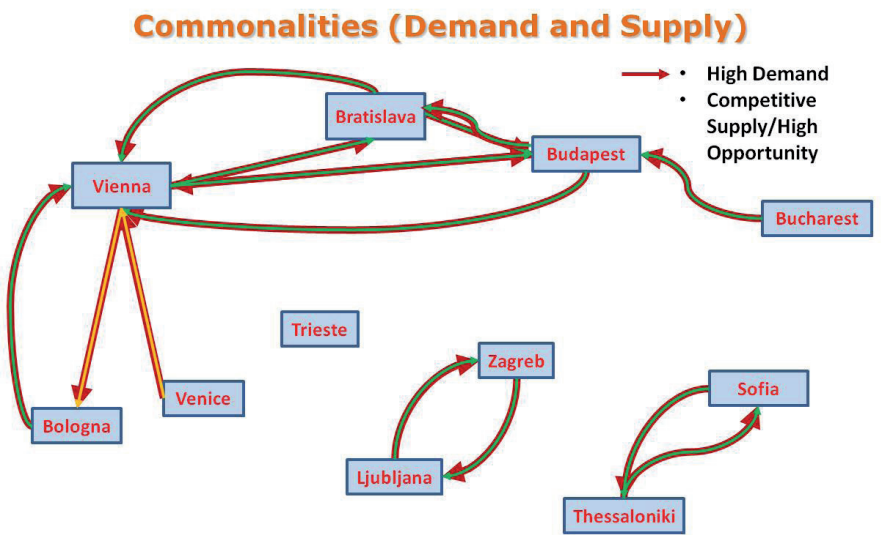

Fig. 10 Commonalities among demand and supply 


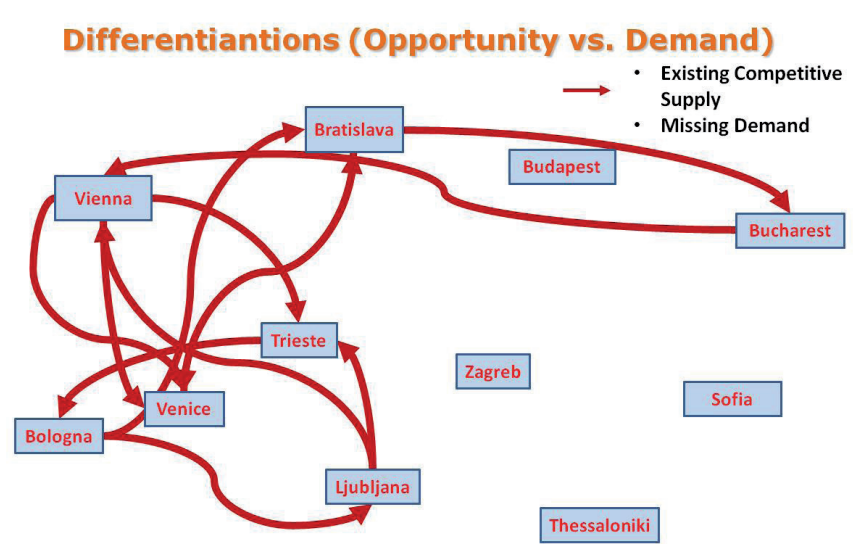

Fig. 11 Missing Demand

It is obvious that there are specific needs for upgrading the rail supply as there is a high demand but not an attractive rail supply for covering the needs and expectations of the passengers. The specific connections between Vienna-Zagreb, Budapest-Ljubljana, Zagreb-Budapest and Sofia-Bucharest must be the first priorities for rail network interventions and upgrading as it is shown in the Fig. 12.

\section{Differentiations (Demand vs. Opportunity)}

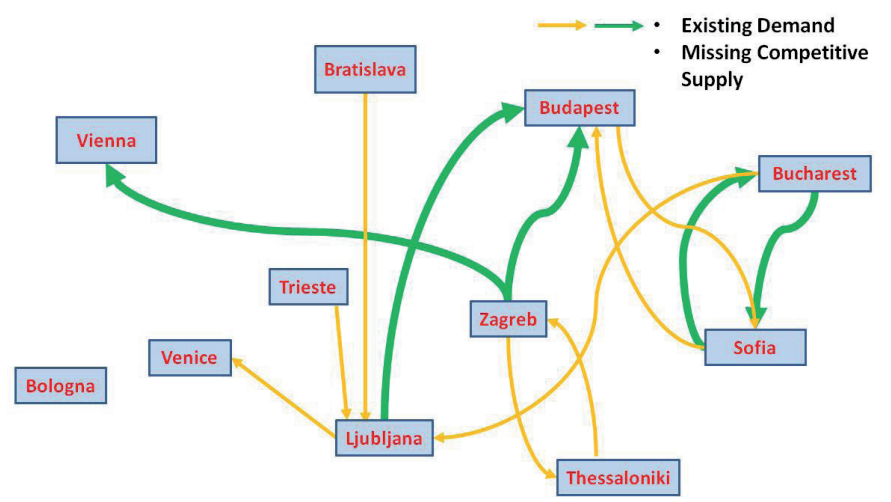

Fig. 12 Missing Competitive Supply

\section{Conclusion}

Overall, rail enhancement opportunities are rather limited, mostly due to infrastructural issues (lack of existing connections) and could only be possible if the existing services were upgraded in terms of frequency, punctuality, comfort and other qualitative parameters.

At regional level there are specific connections between the R4S hubs and other rail hubs of the region, with high number of rail demand. This links can operate as feeders to the international core rail network and must be upgrading and enhanced. At a transnational level, the effort to identify the current status of rail transport and the existing opportunities for intervention was showed a lot of potentials for new rail connections and some other rail connections that must be improved in order to attract more passengers. The intervention would be in the form of the enhancement of the currently offered services and concern the existence of Information Communication Technologies for informing passengers, the harmonization of timetables at a transnational level, in order to minimize waiting time at transit stations and the integrated ticketing in order to facilitate passengers' trips.

In that direction, outside however of this paper's target, a modal split model has been developed and calibrated under this work and calibrated with observed demand and supply data. The model was built in such a way, in the sense of the modal utility functions development, so as to be able to include future services developments and conclude on their impact in transnational trips. The model will be used for evaluating various measures towards the enhancement of rail transport (both the ones examined here as well as other - such as decreasing overall ticket costs, etc.) and justify possible investments in that direction. The model could also be an aid to various stakeholders, public authorities and other relevant actors after the completion of the project, so as to evaluate similar measures and policies, as well update its current databases.

\section{Acknowledgement}

The publication is result of the implementation of the project "Rail Hub Cities for South East Europe" RAIL4SEE, funded by the European Union under the South East Europe Transnational Cooperation Program.

\section{References}

Aifandopoulou, G., Morfoulaki, M., Myrovali, G., Pavlov, D. (2014) Mapping Investments for Improvement of Some Rail Hubs in South East Europe. Periodica Polytechnica Transportation Engineering. 42 (2). pp. 103-110. DOI: $10.3311 /$ PPtr.7446

Armstrong, J., Preston, J. (2010) Rail in the Context of Climate Change: Strengths, Weaknesses, Opportunities and Threats. 12 $\frac{\text { th }}{\text { WCTR, July }}$ 11-15, 2010 - Lisbon, Portugal.

Bruinsma, F. R., Rietveld, P. (1993) Urban agglomerations in European infrastructure networks. Urban studies. 30 (6). pp. 919-934. DOI: $10.1080 / 00420989320080861$

Commissie, E. (2011) White paper, Roadmap to a single European Transport Area, Towards a competitive and resource efficient transport system.

The Council, The European Economic And Social Committee And The Committee Of The Regions, Communication From The Commission To The European Parliament (2013) The Fourth Railway Package Completing The Single European Railway Area To Foster European Competitiveness And Growth.

EC Directorate General for Energy and Transport (2008) Modern Rail, Modern Europe; towards an integrated European Railway Area. DOI: $10.2768 / 22613$

Eisenkopf, A., Kirchner, C., Jarzembowski, G., Ludewig, J., Rothengatter W., McCullough G. (2006) The liberalisation of rail transport in the EU. Intereconomics. 41 (6). pp. 292-313. DOI: $10.1007 / \mathrm{s} 10272-006-0200-9$

Ficzere, P., Ultmann, Z., Török, Á. (2014) Time-space analysis of transport system using different mapping methods. Transport. 9 (3). pp. 278-284. 
RAIL4SEE project (2012) Deliverable „Action 4.3: Regional and transnational flows analysis in a multimodal perspective".

Spence, N., Linneker, B. (1994) Evolution of the motorway network and changing levels of accessibility in Great Britain. Journal of Transport Geography. 2 (4). pp. 247-264.

DOI: 10.1016/0966-6923(94)90049-3

Stamos, I., Mitsakis, E., Grau, J. M. S., Aifadopoulou, G. (2014) A methodology for assessing the impacts of enhanced rail services in South East Europe. Transport Research Arena. Paris

DOI: $10.3846 / 16484142.2014 .916747$
Török, Á. (2014) Environmental Comparism Of Road And Railway Transport: A Case Study In Hungary. International Journal for Traffic and Transport Engineering. 4 (2). pp. 210-219.

DOI: $10.7708 /$ ijtte.2014.4(2).07

World Bank, Transport Unit, Sustainable Development, Europe and Central Asia Region (2011) Railway Reform in South East Europe and Turkey: On the Right Track?. Report No. 60223-ECA 